\title{
Sobrecarga de Planos de Opressão e o Encarceramento Feminino no Sul do Rio Grande do Sul
}

\author{
Oppression Plans Overburden and Female Incarceration in Southern \\ Rio Grande do Sul
}

\author{
Jackson da Silva Leal \\ Universidade Católica de Pelotas - UCPel \\ jacksonsilvaleal@gmail.com
}

\begin{abstract}
Resumo
Neste trabalho se aborda a problemática da dominação masculina e o encarceramento feminino. Trabalha-se analisando os estabelecimentos prisionais mistos destinados originariamente para homens, e por força do incremento do aprisionamento de mulheres, tem de se adequar para recepcionar as mulheres infratoras, duplamente infratoras, dupla ou multiplamente punidas. Utiliza-se uma abordagem, além do referencial predominantemente bibliográfico, elementos empíricos obtidos junto à pesquisa realizada pelo Grupo Interdisciplinar de Trabalho e Estudos Criminais Penitenciários, intitulada 'A prisão dentro da prisão: uma visão sobre o encarceramento feminino na $5^{a}$ Região Penitenciária do Rio Grande do Sul'. Visa-se avaliar quanto se refletem no mundo prisional os estereótipos extramuros e se este reflexo tem seus desdobramentos nas afirmações de direitos, mantendo o mesmo sistema patriarcal de garantias apenas no plano teórico-formal e as dores quotidianas no plano prático e empírico.
\end{abstract}

Palavras - chave: Contrato Sexual; Mulher; Dominação; Encarceramento.

\begin{abstract}
This paper addresses the issue of male domination and female incarceration. The work analyzes the mixed prisons - originally intended for men, but due to an increase in the imprisonment of women, it had to be adapted to receive women offenders: double offending, suffering double or multiple punishments. Our approach, besides the mainly bibliographic references, recurs to empirical evidences obtained from the survey conducted by the Interdisciplinary Working and Study Group on Criminality and Penitentiary, entitled 'A prison within the prison: a vision of female incarceration in the 5th Region Penitentiary in Rio Grande South '. The aim is to assess in which degree the prison stereotypes are reflected in the extramural world, and if this reflexion has influences on the statements of rights, preserving the patriarchal system guarantees only in the theoretical-formal plane, while the everyday sufferings are revealed in the practical and empirical ones.
\end{abstract}

Keywords: Sexual Contract; Woman; Domination; Imprisonment. 


\section{Introdução}

No presente trabalho aborda-se as questões em torno da dominação masculina e apartação por gênero e sua interface com a problemática questão do encarceramento feminino. $\mathrm{O}$ problema da dominação masculina, ademais da problemática diretamente em foco, interage com vários outros campos de atuação e do conhecimento humanos, como política (cidadania, democracia), cultura (educação e comunicação) e outros inscritos nesta dinâmica relacional, todos igualmente conflituosos e produtores de sofrimento; demarcados e traçados historicamente. Os quais deverão ser abordados, obviamente sem a pretensão de esgotar qualquer dos temas, dada a relevância e complexidade que envolve cada uma das discussões/mecanismos pelos quais se desenvolve e se sustenta este processo social, político e cultural de dominação.

Analisa-se a formação político-social na qual está estruturada a sociedade contemporânea, num sentido de avaliar a ordem jurídico-política que desde os primórdios das relações contratuais, já assentava a submissão do sexo feminino ao sexo masculino, legitimando o modelo patriarcal. Contextualiza-se a discussão dentro de uma problemática maior, a globalização e suas facetas (instrumentos) de dominação, inclusão pela exclusão, e como este processo mundial de homogeneização reflete em termos estruturais nas relações de gênero e política.

Segue-se para o objeto principal deste trabalho, que diz respeito à questão da mulher encarcerada e as relações de dominação e de sobreposição de cargas de dominação/punição que são potencializados no ambiente carcerário, sobretudo, quando em estabelecimento misto, destinado para homens e mulheres.

Ademais da análise teórica realizada, parte-se, em específico, de dados obtidos em pesquisa realizada pelo Grupo Interdisciplinar de Estudos e Trabalho Criminais Penitenciários (GITEP) ${ }^{1}$, intitulada A prisão dentro da prisão: uma visão sobre o encarceramento feminino na $5^{\mathrm{a}}$ Região Penitenciária do Estado do Rio Grande do $\mathrm{Sul}^{2}$, que pesquisou a condição de subalternidade das internas de presídios na área geográfica do sul do Estado do Rio Grande do $\mathrm{Sul}^{3}$.

Com este trabalho, visa-se avaliar quanto se refletem no mundo prisional, os estereótipos extramuros e o quanto este reflexo tem seus desdobramentos na afirmação de direitos, mantendo o mesmo sistema patriarcal, mantendo as garantias, apenas no plano teórico formal.

\section{Demonização do feminino e (des)construção histórica}

A dominação masculina vem sendo desempenhada desde tempos imemoráveis. Outrossim, sob o argumento de que seria resultado da natureza humana, ou da natureza da mulher e da cultura do homem, nasce o mito cultural de que a mulher é apenas uma extensão da natureza e o homem a expressão cultural. Assim, faz-se com que a cultura ocidental seja masculina e opressora desde que o homem conseguiu apreender os processos de manipulação/dominação da natureza.

Primitivamente se conjectura que as mulheres tenham sido aceitas e reconhecidas plenamente em suas características e potencialidades, como detentoras de uma vital importância para o bom andamento tribal, visto o seu poder e vinculação com os deuses que lhes permitiam a possibilidade de gerar a vida e também com isso, influenciar na fertilidade da terra. Em um período, o qual, não havia sido, ainda, forjada a propriedade privada e tampouco apropriada por algum homem. Desta forma, o valor imperante nos grupos era o da cooperação e o sentimento de solidariedade (MURARO, 2005). No entanto, como proposto, são conjecturas sem comprovações científicas sólidas.

O que é notório e histórico é que, desde os tempos mais remotos, em termos de sociedade constituída politicamente, nas sociedades que pensam o político na Grécia Antiga, a mulher já era subjugada e submissa ao homem, aos detentores do conhecimento e da política. Legado transmitido à civilização Romana, que por sua vez aprofundou essas desigualdades de gênero (STEARNS, 2007).

Não bastasse esta dominação ascendente, com a criação da instituição familiar como membro nuclear da sociedade política, tem-se o cerceamento da sexualidade feminina devido à necessidade econômica de apropriação e controle sobre a transmissão por herança dos bens de família, tendo em vista que esta (a mulher, esposa, mãe, obediente e submissa) estava relegada ao espaço privado, mais que isto, espaço doméstico, ao contrário do homem, que adquiriu um espaço público de privacidade, onde não é retirada a sua livre e espontânea atividade sexual e afetiva, demonstração de sua virilidade.

Com a cristianização do mundo romano e tido como bárbaro acrescenta-se à posição da mulher como naturalmente submissa, o fator divino - extra-humano que requeria obediência e abnegação constantes, devido estarem diante da vigília permanente do senhor, todo poderoso - onipresente, onisciente e onipotente. $\mathrm{O}$ que confirmava e confinava as mulheres dentro do lar, cuidando dos filhos. Esta era a mulher normal, as que 
procuravam mudar esta lógica eram tidas como loucas, carecendo de purificação, tratamento e isolamento, quando não queimadas como bruxas.

Não obstante todo esse movimento político cultural, mesmo assim, embora todos os argumentos de inferioridade intelectual, inaptidão para a vida longe do lar, ou melhor, no mundo público, fraqueza física ou psicológica, ou qualquer outra maneira de tentar confirmar a subalternidade do outro; ainda assim, as mulheres, conseguiram alçar posições sociais, em diversos momentos da história da 'idade das trevas'.

Houve mulheres, como abadessas que tomavam conta, gerenciavam vários monastérios na França, mesmo dentro de uma instituição Católica, altamente sexista; ressalta-se também a coroação de rainhas pelo mesmo processo de coroação dos reis em Reinos, e a produção intelectual e cultural, salientando que antes mesmo de os homens influenciarem de maneira incisiva com suas obras sobre educação, mulheres já haviam se projetado sobre esse tema com brilhantismo. A medicina acadêmica emergente teve que guerrear para conseguir este monopólio, pois quem detinha os conhecimentos iniciais sobre medicina eram as curandeiras. Curiosamente, é a mesma classe médica que as diagnostica como loucas, descontroladas, desfavorecidas fisicamente, psicologicamente e intelectualmente (STEARNS, 2007).

Ainda, referente à participação política, encontra-se documentos esparsos provando a presença das mulheres em decisões importantes nas suas comunas e povoados (STEARNS, 2007). Acabando com os argumentos da inferioridade de todas as formas e, demonstrando, que exemplos como Joana D'Arc não foram sombras solitárias e esparsas perturbadoras da paz, como de regra leciona-se na literatura histórica tradicional.

Ao passo que, diante desta luta e possibilidade de sucesso ou se transformar no insucesso de toda causa ou objetivos cristãos pré-capitalistas de competição, produção, demonstração de poder e atribuição de dor ao prazer, a Cristandade, através do fenômeno da Santa Inquisição dizima predominantemente as mulheres. Assim, aprofunda ainda mais o repúdio à sua cultura, sua história, corrompe seus valores e características, atributos e costumes, transformando-as em loucas, possuídas, bruxas (...).

Passa a gerir o verdadeiro demônio desestabilizador da sociabilidade humana, a revolução científico produtiva capitalista que se desenvolve nos séculos porvir, tendo a mulher como seu antagônico e oponente, dentro de casa ou no fundo de um calabouço, simbolizada pela 'maldita' Eva, das santas escrituras, que a todas condenou, eternamente.

O calabouço veio com a modernidade, sob a bandeira da democracia, disfarçado de igualdade de escolhas e oportunidades para todos; potencializado pelo fenômeno, não novo, mas em ampla expansão chamado globalização que extrapola os limites de possibilidades e oportunidades de lucro. Necessitando cada vez mais de demanda, de consumidores desta lógica que não se trata apenas de consumo, mas de uma ideologia de tudo ser quantificável - para alguns em cifras, ou em bolhas de champanhe ao final de cada ano; para outros em minutos, dias, anos...riscados e perdidos em uma parede suja de uma cela.

\section{o Contrato sexual}

O ponto convergente do contrato social se deu com a juridicização da organização social, reflexo da concentração de poderes no ente público estatal. Neste sentido, as decisões são tomadas no espaço público, mas quando os anseios privados clamam serem 'publicizados', Bauman assevera:

(...) o aumento da liberdade individual pode coincidir com o aumento da impotência coletiva na medida em que as pontes entre a vida pública e privada são destruídas ou, para começar, nem foram construídas; ou, colocando de outra forma, uma vez que não há uma maneira obvia e fácil de traduzir preocupações pessoais em questões públicas e, inversamente, de discernir e apontar o que é público nos problemas privados (BAUMAN, 2000, p. 10).

Pierre Bourdieu, por sua vez, trabalha com o fato de que as atividades públicas de representação e tomada de decisões - onde são desenvolvidos e ostentados os bens simbólicos de cada indivíduo, onde a mulher não alcança, onde não lhe é permitido alcançar; onde se dão as trocas de honra e parte-se de um pressuposto que isto só é possível entre iguais, ou seja, entre duas pessoas que possuam honra, o que não é o caso da mulher, mero objeto da honra masculina.

Ademais, Jussara Reis Prá aclara, [as mulheres] "quando buscam espaços de poder no tradicional "mundo masculino"" (PRÁ, 2004. p. 45) sendo via de regra neles inseridas em conexão com o 'mundo feminino', o exercício de atividades relacionadas com saúde, educação, família torna a vida pública extensão da função maternal/doméstica, reforçando a clássica dicotomia que atrela as mulheres a esfera privada da reprodução, de afazeres domésticos e cuidado dos outros, e os homens à esfera pública da produção, da economia, da política e das decisões. Esta dicotomia é consequência lógica da sociedade em que vivemos, 
permeada de tradição. Como propõe Zygmunt Bauman "induz a crer que o passado amarra o presente; prevê, no entanto, (e desencadeia) nossos esforços presentes e futuros de construção de um passado pelo qual precisamos ou queremos ser amarrados" (BAUMAN, 2000. p. 136).

Na mesma linha, como salienta Anthony Giddens, vivemos em uma sociedade pós-tradicional, mas não por viver em uma sociedade que superou ou escassa de tradições; mas, em uma sociedade referência de um excedente de tradições, com um excesso de leituras do passado competindo pela aceitação (GIDDENS apud BAUMAN, 2000).

Para Bauman o sentido próprio da tradição está ligado a não aceitação ou negação em reconhecer a origem humana das regras e das normas, sociedade que se imagina modelada e guiada por força externa, incorporando nas instituições a ideia de que seus membros não devem contestar: a de que as instituições não foram criadas pelo homem, pelo menos não pelos seres humanos atuais. As instituições foram criadas por espíritos, por ancestrais, por deuses ou heróis, não é produto humano. Essa tradição ou excesso permeia o contrato social e o mundo público das decisões, ao mesmo tempo em que relega e delega à mulher ao/o espaço privado, doméstico, transformando-se em um contrato sexual, do qual a mulher não pode furtar-se de cumprir, sob pena de carregar a culpa de impedir o crescimento societário, visto estar deixando de lado o núcleo celular desta sociedade, a família patriarcal. Como propõe Joaquín Herrera Flores:

como consecuencia de esa 'naturalización' de valores masculinos y femeninos, el patriarcalismo ha inducido una construcción social del derecho y la política instituyendo dos situaciones: una visible, la llamada esfera de los iguales ante la ley y otra invisible, la de los y las diferente (FLORES, 2005. p. 31).

Assim, o contrato social restringe a liberdade coletiva e proclama produzir a mesma liberdade, a segura liberdade individual, contrariando a esta ideia, Bauman propõe:

se a liberdade foi conquistada, como explicar que entre os louros da vitória não esteja à capacidade humana de imaginar um mundo melhor e de fazer algo para concretizá-lo? E que liberdade é essa que desestimula a imaginação e tolera a impotência das pessoas livres em questões que dizem respeito a todos (BAUMAN, 2000. p. 9).
Ou ainda, na esteira proposta por Joan Scott para quem "a liberdade requer um ato de escolha, pelo qual algumas diferenças são minimizadas ou ignoradas enquanto que outras são maximizadas e postas a se desenvolver [...] desde quando é permitido abrir mão de seu sexo" (SCOTT, 2005. p.15)? Propõe a autora, visto a maximização das características que são utilizadas para a sua subordinação (da mulher) enquanto minimizados seus potenciais.

Além disso, diante dessa impossibilidade de escolha, afigura-se outra dimensão de impedimento, como permite a avaliação de Zygmunt Bauman (1998), no mundo pós-moderno de estilos e padrões de vida "livres" e concorrentes, há ainda um severo teste de pureza/pertença que se exige que seja transposto por todo aquele que solicite ser ali admitido: tem de mostrar-se capaz de ser seduzido pela infinita possibilidade e constante renovação promovida pelo mercado consumidor, de se satisfazer com a possibilidade de vestir e despir identidades.

No entanto, esta possibilidade, o passaporte para o mundo pós-moderno, não é afeito às identidades atribuídas, ou possíveis ao feminino. Como diz Bauman: "nem todos podem passar nessa prova. Aqueles que não podem são a 'sujeira' da pureza pósmoderna” (BAUMAN, 1998. p.23). Neste sentido:

se os estranhos são as pessoas que não se encaixam no mapa cognitivo, moral ou estético do mundo (...) se eles, portanto, por sua simples presença, deixam turvo o que deve parecer transparente, confuso o que deve ser uma coerente receita para a ação, e impedem a satisfação de ser totalmente satisfatória; se eles poluem a alegria com angustia, ao mesmo tempo que fazem atraente o fruto proibido; se, em outras palavras, eles obscurecem e tornam tênues as linhas de fronteira que devem ser claramente vistas; se, tendo feito tudo isso, geram a incerteza, que por sua vez dá origem ao mal-estar de se sentir perdido então cada sociedade produz esses estranhos (BAUMAN, 1998. p. 27).

Situação e estágio de dominação simbólica, como coloca Pierre Bourdieu, "violência suave, insensível, invisível a suas próprias vítimas” (BOURDIEU, 2005. p.7), inclusive afetando sua clientela masculina aos quais não podem fugir do papel opressor e opressivo, ou seja, virtuosidade que é imposto ao homem demonstrar, um papel preestabelecido independentemente de negação, aceitação, 
questionamento: "ele não pode agir de outro modo, sob pena de renegar-se" (BOURDIEU, 2005. p.63).

Esta virilidade ou modelo de ser masculino que consiste na capacidade reprodutiva e sexual, também como aptidão para o combate, o exercício de violência, ser alheio ao próprio sofrimento e, principalmente, ao sofrimento dos outros, acredita-se ser este o traço distintivo da virilidade, como bem simbólico, imposto à esfera masculina. Estes atributos refletem também no contrato social, reafirmando a sexualidade do contrato.

Com a manutenção desses discursos, se mantém identidades femininas e masculinas, diferentes e opostas, quando não complementares, fazendo com que as mulheres não possam pensar a si mesmas através da própria experiência, da própria história, as obriga a medir-se com o homem, para encontrar a medida de si, permitindo com que os preconceitos permaneçam intactos e ao invés de ser o propiciador de soluções, retoma o persistente conflito.

\section{Modernidade das Amazonas ou das vítimas das sobrecargas de opressão}

A democracia tem como seu fundamento primordial a igualdade de todos perante a lei, após diversos aprimoramentos destas democracias, e também dos sistemas jurídicos, sociais e políticos, a democracia se reveste, ao menos, de certa igualdade formal.

Esta igualdade formal é embasada por uma homogeneização cultural produzida pela globalização, que por sua vez impulsiona e potencializa os postulados teóricos democráticos de igualdade e liberdade, desta forma a homogeneização produzida conduz a uma análise abstrata das relações sociais.

Um exemplo que deixa muito claro a falta de autonomia e liberdade é a compulsoriedade do dever-ser mãe, imposta culturalmente como condição para que a mulher possa, apenas por essa via, realizarse como ser, socialmente aceita ou ainda, reproduzindo as expectativas naturalmente instituídas. Como bem aponta Tânia Navarro Swain:

(...) em seu livro As guerrilheiras, vemos o assalto das mães, que tomam o lugar das Amazonas livres, alegres e independentes [...] instaurou o poderoso reino das mães, criando o mito da "mulher" e, ainda melhor, a "verdadeira mulher. A mãe e a esposa, aquela que encarna a diferença, aquela que aceita a marca da especificidade, aquela que assume a inferioridade e não existe senão para e pelo olhar do outro (SWAIN, 2007, p. 95).
Assim, a modernidade delimita a identidade feminina entre dois polos antagônicos, as mulheresmães, eternamente submissas, do lar, do pai, do Estado e as amazonas guerreiras, que se propõem a ingressar, ainda que irruptivamente, no espaço público e tentar subverter a lógica sistêmica que as apartam desses espaços; como aponta novamente Swain, no sec. XVII "uma república de mulheres que viviam sozinhas, sem ter homens com elas" (SWAIN, 2007, p.90).

Nesta esteira, a mulher crítica e reflexiva por muito tempo, e continua sendo, demonizada - qualidade esta atribuída e manipulada politicamente pela ciência. Desde então, estrutura-se a figura da mulher submissa a afeita apenas ao espaço doméstico, para o qual, seria necessária uma capacidade intelectual diminuída, bem como capacidades psicológicas compatíveis com seu papel de cuidado exclusivo da família. Em suma, parir, criar e padecer.

É esta vedação a fala, a pergunta e a falta de respostas que em muito contribuem para o impedimento da democracia real (participativa), mantendo-se uma ficta democracia representativa. Neste contexto, as mulheres são apartadas dos principais núcleos políticos. Na melhor das hipóteses, servem na manipulação de cargos onde quem de fato decide é a mesma estrutura patriarcal.

Ao longo da história a mulher tem desempenhado um papel fundamental no desenvolvimento da família, um papel que nunca foi valorizado. Essa desconsideração para com o sexo feminino é histórica como salienta Heleieth Saffioti: "quando se afirma que é natural que a mulher se ocupe do espaço doméstico, deixando livre para o homem o espaço público, estáse, rigorosamente, naturalizando um resultado da história" (SAFFIOTI, 1987. p. 11). No mesmo sentido, Zygmunt Bauman propõe: "nada é mais artificial que a naturalidade; nada é menos natural do que se lançar ao sabor das leis da natureza. O poder, a repressão e a ação propositada se colocam entre a natureza e essa ordem socialmente produzida na qual a artificialidade é natural" (BAUMAN,1999. p. 15).

$\mathrm{O}$ que contemporaneamente se absorve como natural é fruto da carga de opressão sofrida pela mulher ao longo da história, conforme a cultura são mutiladas, censuradas e subjugadas. São as mulheres que carregam o maior peso da pobreza que atinge, atualmente $2 / 3$ dos habitantes da terra. E quando têm sua presença tolerada, pela modernidade, no mercado de trabalho, continuam responsáveis pelo ambiente doméstico, resultando em uma dupla jornada de trabalho.

Assim, tem-se a intolerância mascarada de tolerância com o claro propósito de mais uma vez ressaltar a superioridade masculina. Quem tolera não 
aceita, nem respeita o valor do outro, é sim 'generoso' para com suas imperfeições, sutilmente reafirmando sua inferioridade. As mudanças nas relações domésticas foram no sentido de ajudar a dividir as despesas do lar, as mulheres aos poucos passavam à vida pública, mal remunerada e explorada, porém, sempre com a submissão no âmbito privado em relação ao macho dominante, ou seja, dupla submissão. Ou ainda, quando as diferenciações que são constituídas socialmente outorgando o espaço público e da produção para o homem, ao passo que relega o cuidado e a reprodução à mulher. Como conclui Jussara Reis Prá: "enquanto o primeiro leva à autonomia econômica e ao reconhecimento cidadão, o segundo pode gerar situações de dependência e cidadanias delegadas, de segunda ordem" (PRÁ, 2004. p.47). Badinter propõe ainda:

frustrações maiores para os meninos que para as meninas, numa sociedade que demonstra uma admiração irrestrita pelo sucesso econômico, porém frustrações que serão cada vez mais compartilhadas pelas jovens de nossa sociedade, que também proclama a igualdade entre os sexos (BADINTER, 2005. p. 86).

$\mathrm{Ou}$ como assevera Eduardo Galeano se posicionando frente à estrutura sexista que é instaurada desde a espiritualidade cristã ocidental:

Se Eva tivesse escrito o Gênesis, como seria a primeira noite de amor do gênero humano? Eva teria começado por esclarecer que não nasceu de nenhuma costela, não conheceu qualquer serpente, não ofereceu maçã a ninguém e tampouco Deus chegou a lhe dizer 'parirás com dor e teu marido te dominará'. E que, enfim, todas essas histórias são mentiras descaradas que Adão contou aos jornalistas (GALEANO, 2007. p. 70).

Estes códigos de ambivalência criam "o mundo social como corpo de realidade sexuada e como depositário de princípios de visão e de divisão sexualizantes" (BOURDIEU, 2005. p.18). Trabalhando claramente com a criação de valores identificadores e legitimadores do poder masculino sobre os inversos, femininos; automatizados, inquestionáveis e imutáveis como consequência lógica naturalmente artificial.

Diante das análises sociopolíticas e culturais feitas, releva passar a analisar estas relações de gênero e a problemática que as envolvem, no interior do sistema carcerário, pois essa mulher, quando impulsionada a adentrar no mundo publico masculino, seja por melhores condições de vida, seja por pura necessidade, seja por aceitação, sempre o faz, em situação de desvantagem. A partir do momento que este indivíduo ingressa no mundo da competição, da produção, do poder; não raras vezes se vê em situações de ilegalidade, por vezes conscientemente e por não ter escolha, por vezes inconscientemente.

Todavia, a mulher, quando transgressora da lei penal, infringindo e atentando contra algum bem jurídico penalmente tutelado, depara-se com a ideia socialmente aceita da mulher como dupla, ou multiinfratora, pois extrapola não apenas a esfera jurídica de outro, mas sim a dela mesma, sua própria esfera pessoal subjetivo valorativa socialmente posta, caracterizando inadaptação à vida privada, caseira, submissa, e suas limitações e dependência, rompendo com a ideia estereotipada de mulher, tendo de suportar da mesma forma que o homem a punição por infringir tal ordem, neste caso, dupla ordem. Assim:

é a lei dos homens, o judiciário dos homens, a justiça dos homens que encarcera as mulheres... 'esposas e mães falhas'. Não há nada na lei, ou muito pouco nas políticas criminais e penitenciárias recentes, que enfrente $\mathrm{e}$ afronte significativamente às sobrecargas de punição (...) pelo contrário, na conjuntura atual o que existe é a ampliação das mesmas (CHIES, 2008b. p.93).

No mesmo sentido, "toda expressão de poder por parte de mulheres desembocava em punição" (ZORDAN, 2005. p.332). Demandando suplícios pedagógicos às bruxas, que não se dobram ao masculino.

Neste cenário de dominação por gênero, impõe-se abordar essa dinâmica relacional e o sistema prisional, bem como as perversidades e os reflexos que o envolvem, este sistema de justiça criminal que julga e encarcera as amazonas, mulheres que não se enquadraram no mapa cognitivo da modernidade patriarcal, no papel da submissão, da filha, da esposa e da cidadã sem vez e voz. 


\section{Duplamente transgressora, duplamente punida}

Após analisar as origens da dominação, que se propõe e/ou é proposta como domínio político, cultural, refletindo diretamente e determinantemente no social e no jurídico demonstra-se que a formulação societária que se conhece, apresenta-se povoada por um predador natural que se aloja nos inconscientes individuais, e, com isso, dos coletivos; condicionando as percepções que os indivíduos têm do seu mundo e da forma como se posicionar nele.

De tal forma é a adoção deste predador e de seu código de valores e percepções - naturalizadas - que permite com que este predador relegue à marginalidade os que a ele se opuserem, assim como os saberes que pretendam romper com a lógica 'normal' por ele estabelecida.

Como propunha Carole Pateman: "um indivíduo livre e igual aos outros deve, necessariamente, concordar em ser dominado por outro [...] há uma variedade de formas de livre acordo, mas o contrato se tornou o paradigma da obrigação voluntária" (PATEMAN, 1993. p.67). Boaventura prossegue ainda, propondo que o sistema atual da globalização hegemônica, permite com que trocas desiguais canibalizem as diferenças, ao invés de permitir o diálogo e a confraternização estando "armadilhadas por silêncios, manipulações e exclusões" (SANTOS, 2006. p.86).

Como verificado na pesquisa realizada pelo GITEP4,"percebe-se que a mulher está inserida numa rede de controle social mais ampla e rígida, desde sua posição na família patriarcal, até as estrategias psicopatologizantes de suas condutas consideradas como desvio" (CHIES, 2009, p. 253).

Assim, enquanto 'complexificam' as relações modernas, mais se acirram as desigualdades, que são evidentes com relação a gênero, raça, classe social ou qualquer outra forma de diferenciação, procurar-se-á apenas abordar alguns fundamentos e explicações em torno destas disparidades de benefícios e encargos gerados pelo sistema, como propõe Santos: "a distribuição extremamente desigual dos custos e das oportunidades produzidos pela globalização neoliberal no interior do sistema mundial, residindo aí a razão do aumento exponencial das desigualdades sociais" (SANTOS, 2003. p. 13) .

Contemporaneamente, as abordagens que buscam articular gênero com o desenvolvimento, se atentam para que, as desigualdades de gênero não podem ser explicadas apenas pelas dinâmicas econômicas, evidenciando que o crescimento econômico não é neutro no que se refere às relações entre gênero, e que, como já dito - homens e mulheres não se beneficiam igualmente dos possíveis resultados e que as cargas de pobreza não são distribuídas igualmente.

Nesse sentido, permite fazer uma análise das dimensões sobrepostas de opressão ou sobreposição de planos de dominação - donde as mulheres estão sujeitas à potencialização desta sobreposição impetrada pelo sistema. Sobreposição ainda mais visível e dramática no âmbito e interior do sistema carcerário, abordagem quem, em especial, interessa a este trabalho.

As mulheres, além de carregar toda a pesada carga cultural de estereótipos e papéis preestabelecidos, relegadas ao segundo ou último plano no âmbito social e político, quando, no cumprimento de sua pena privativa de liberdade, vêm-se, novamente, às voltas com todos os estereótipos, a partir de então como responsáveis pela ampliação de sua dor na punição.

Começa-se propondo que a escassez de trabalhos e projetos envolvendo a problemática do sistema carcerário feminino sendo um indício fortíssimo de que estas estão relegadas a cumprir sua pena acompanhada do esquecimento, outrora a pena era a fogueira, contemporaneamente é a solidão.

Fato este, da solidão, corroborado quando da verificação que a grande maioria dos relacionamentos se desfaz quando a mulher é selecionada pelo sistema de justiça criminal e passa a cumprir pena privativa de liberdade; enquanto o companheiro está livre, ou mesmo, quando ambos cumprem pena, e ele obtém alguma modalidade de livramento antes dela, apenas $37 \%$ das mulheres encarceradas recém-visitas sociais; situação diversa quando da situação inversa, quando o homem cumpre pena, em grande parte dos casos, é acompanhado pela esposa, companheira, mãe, irmã, ou alguma outra figura feminina representante da ternura, $86 \%$ dos homens presos recebem as visitas sociais regularmente (CHIES, 2009).

Outro elemento de resultados profundamente dolorosos para a reclusa é o fato de haverem no Brasil, apenas 58 estabelecimentos exclusivamente femininos, e $508^{5}$ mistos, reflexo do silêncio das políticas penitenciárias quanto ao gênero feminino. Acarretando que milhares de detentas tenham que cumprir pena longe de suas comarcas, e os laços afetivos que já são abalados em virtude da falha para com seu papel de mulher, desfaz-se quando somada a distância.

Outro elemento importante que se faz ausente nas instituições carcerárias é a estrutura adequada às particularidades femininas, desamparadas de quadro funcional e profissional adequada às mesmas, necessidade que vai desde ao acesso a saúde, com 
médicos ginecologistas e obstetras para as detentas gestantes ou que venham a adquirir tal situação posterior ao momento de seu aprisionamento; até mesmo artigos de higiene pessoal, que se faz mais peculiar em relação à mulher, em decorrência do ciclo menstrual, isto sem levar em conta a vaidade, atribuída naturalmente à mulher, o que é desconsiderado a partir do momento em que esta comete o delito e é privada de usufruir (CHIES, 2009).

Até a ausência de estrutura de creche e berçário, onde a reclusa poderia amamentar e começar a criação de seu filho com condições minimamente dignas, se é que isto é possível em uma instituição carcerária, de acordo com dados da CPI do Sistema Carcerário apenas $27,45 \%$ dos estabelecimentos tem estrutura para gestantes, 19,41\% contam com berçários e somente $16,13 \%$ possuem creches $^{6}$; não obstante mais de $70 \%$ das mulheres encarceradas na $5^{\mathrm{a}}$ Região Penitenciária do Rio Grande do Sul possuam filhos, e tal estatística provavelmente se estenda ao restante do país (CHIES, 2009).

Situação particularmente importante é a da verificação do aumento exponencial das taxas de encarceramento feminino, contrariando o argumento de que o aumento da criminalidade se deve à impunidade, havendo um aumento de $37,47 \%$ da população carcerária feminina, aumento reflexo ao ingresso das mulheres no mercado de trabalho em condições desiguais, de oportunidades, de formação profissional, de remuneração, etc.

As mulheres representam contemporaneamente $6,12 \%$ da população prisional no Brasil. Em números mais precisos, no Rio Grande do Sul, a população carcerária feminina, em 2007 era de 1.045 mulheres. Em geral, mais de $50 \%$ na $5^{\text {a }}$ região penitenciária do Rio Grande do Sul, por delitos relacionados à entorpecentes, na posição de 'mulas' para o tráfico de drogas, ocupando desta feita, uma posição subalterna na profissão criminosa, em geral, como única fonte de renda e subsistência da família, haja vista tenham, mais de $50 \%$ tenham nível de formação fundamental incompleto, o que se reflete na grande e massiva maioria como sendo ocupantes de posições econômicas de baixa qualificação e significância social, na maioria do lar e vinculadas ao imaginário doméstico (CHIES, 2009).

Outros elementos importantes na operacionalidade e governabilidade do sistema penitenciário nacional é o acesso a direitos. Tais como: o acesso a visita intima, como é verificado, para as mulheres é exigido requisitos mais rigorosos, em comparação com os reclusos homens. Para essas, deve ser comprovada relação conjugal, enquanto que para os homens, basta a requisição da carteirinha para acesso à visita íntima - ressurgindo os estereótipos da castidade feminina e da liberdade sexual masculina e o direito a esse espaço de privacidade.

Ainda, quando do relacionamento entre homem e mulher presos, nunca esta recebe a visita íntima e sim oferta a visita ao seu companheiro, retomando novamente os papéis de disponibilidade do corpo feminino, como mero repositório reprodutor do varão. Não só não se utiliza os mesmos critérios para concessão de tal direito, como também não se disponibiliza locais adequados para a realização da visita, em quase a totalidade dos estabelecimentos, não são respeitadas as condições mínimas de dignidade condizente à sua privacidade, sobretudo neste momento particular do encontro, onde acontecem as relações afetivas (CHIES, 2009).

Outro direito que se vê ofuscado e novamente trazendo tradicionais estereótipos e restrições é no que diz respeito as atribuições de trabalhos prisionais, e cursos profissionalizantes, não apenas pelo fato de gerar a remição, mas pelo fato de poder ser um futuro elemento propiciador de alternativas em uma possível e provável vida extramuros (após o cumprimento da pena).

Todavia, a mulher está restrita, nas possibilidades que lhe são dadas, a trabalhos relacionados à limpeza e atividades relacionadas com o âmbito doméstico, assim como os cursos a disposição, em geral, de corte e costura e congêneres, sem grandes possibilidades econômicas no mundo do mercado consumidor competitivo.

E por fim, o acesso à assistência jurídica e celeridade processual; que é verificado que, mesmo a população carcerária masculina sendo maior, não é argumento para as detentas não terem acesso a esse direito ou verem seus direitos demorarem mais a serem analisados, informação sobre seu processo, demora em seus pedidos de toda ordem, por revisão de penas, etc. $\mathrm{O}$ número de mulheres que respondem ao processo criminal presas provisoriamente, ou seja, sem condenação, é expressivo e indicativo desse imaginário da dupla transgressão e justificador das múltiplas punições e denotativo da vulnerabilização social, política e jurídica do gênero feminino:

(renovando) as motivações do controle do feminino e da mulher, conduzindo nossa experiência societária da inquisição à objetivação da mulher como mercadoria de consumo; da bruxa à prostituta, permeada pela 'mulher honesta', todas culpadas, todas criminalizáveis, todas punidas (CHIES, 2009, p. 267). 
Não que este seja o último plano de apartação, pois as descrições acima realizadas não são taxativas ou restritivas, apenas pelo fato de ser impossível esgotar os planos de dominação que se processam no âmbito do sistema carcerário, sobretudo os dos estabelecimentos mistos, no presente trabalho; apenas procura-se traçar brevemente o panorama carcerário feminino nacional e em especial da $5^{\text {a }}$ Região Penitenciária do Rio Grande do Sul.

Demonstra-se o quanto o sistema punitivo carcerário utiliza-se de mecanismos de castração e subtração da feminilidade, transformando-as e reconhecendo-as como mulheres-homens, por terem infringido a lei dos homens e, portanto, terem de sofrer como se tal fossem, pelas feições que adquirem pela truculência institucional e quotidiana das necessidades não supridas e sofrimentos e necessidades suprimidas e também como forma estratégica de defesa durante o cumprimento da pena. Esta estratégia institucional de castração da identidade feminina é utilizada pedagogicamente para serem produtoras da ordem vigente e inquestionável do capitalismo; e mães com seu eterno reino de silêncio e segurança nos braços do pai, no colo do marido e do assistencialismo do Estado.

Conclui-se a abordagem sobre a sobreposição das cargas de opressão/dominação "e que isto traga como resultado que nem elas sejam vistas como mulheres reais, autênticas delinquentes, nem verdadeiras prisioneiras e, portanto, que as prisões de mulheres não sejam autênticos cárceres" (CHIES, 2008. p.85).

E por isso, absurdo falar em modelo universal de cidadania e dignidade; de um modelo fechado, acabado e homogêneo de direitos humanos, capaz de eleger prioridades e necessidades referentes às vitimas do patriarcalismo, quiçá protegê-los.

São vários os subterfúgios utilizados pelo sistema para descartá-lo, afinal de contas é um indivíduo falho ou talvez não seja nem um indivíduo, pois nasceu mulher, de cor não-branca, veio a ficar pobre e foi selecionado pelo sistema de justiça criminal. A sobreposição que se dá no plano cultural e social, reflete diretamente ao plano jurídico-político, que por sua vez é o legitimador e ao mesmo tempo instituidor, além de reforçar a ordem desordenada do sistema da sobreposição de planos de opressão/dominação e apartação.

Conferir um conteúdo emancipatório a noções como cultura, direitos ou cidadania é a condição para uma utilização estratégica de ditos conceitos estratégia chave articuladora das exigências do reconhecimento e da distribuição - como proposto por Boaventura "de uma igualdade que reconheça as diferenças e de uma diferença que não produza, alimente ou reproduza desigualdades" (SANTOS,
2003. p. 43).

Seguindo ainda a linha proposta por Boaventura Santos, vale dizer que vivemos em um mundo/espaço tempo paradoxal, no qual a cultura ocidental é tão indispensável quanto inadequada para compreensão e transformação social. Trata-se de atentar para, se a crítica deve ser feita de dentro do sistema metaestável ou pressupõe a exterioridade das vítimas para a sua modificação, dado que apenas fizeram parte da modernidade pela exclusão, dominação e sofrimento punição.

\section{Considerações Finais}

Neste sentido, no intuito de poder criar, ou começar a, uma inteligibilidade que possa romper com a lógica atual e bem antiga da dominação patriarcal e planejar o traçado de outros rumos de sociabilidade de caráter emancipatório, a conclusão ou uma das possibilidades, passa pela criação da cidadania cosmopolita e multicultural como um fim e como um meio à implantação de uma consciência cyborg como preleciona Donna Haraway, rebelde como prefere Alain Touraine, ou ainda, 'insurgente' para Boaventura de Sousa Santos. Tal consciência teria como marca a resignificação de símbolos opressores que tanto marcaram/estigmatizaram e assim continuam, como nas palavras de Frei Beto: "A marca do batom é vermelha, cor das bandeiras libertárias e, também, do sangue derramado pela opressão ${ }^{7}$ ".

A luta antipatriarcal contra um sistema axiológico que domina, não só, mas principalmente as mulheres acarreta a exclusão das mesmas dos privilégios sistemáticos e ocasiona dores indescritíveis, potencializadas ao extremo no ambiente carcerário. Busca-se um espaço e um tempo próprio, diferente do sancionado pela cultura opressora, pois sem a conquista de uma consciência livre e autônoma nada se conseguirá modificar.

A modificação passa, pela inevitável rediscussão em torno das concepções de liberdade e igualdade. Diante da impossibilidade da plena realização de ambas, entra em cena a dinâmica da política. E é nesta que se pode romper, com a dominação que por característica imanente é sempre totalitária na medida em que é sempre incompetente para transformar todos em exatamente iguais. Há não só uma incompetência, como também uma impossibilidade e aí reside a possibilidade da subversão.

As concepções multiculturais procuram evitar a caída em reducionismos igualitários e quantitativos, e captar a multiplicidade dos diferentes interesses reais de gênero que permitiria a criação de estratégias de mudança que superariam/subverteriam as 
desigualdades e a dominação que envolve a todos e refletem de maneira mais intensa nas mulheres, as quais sofrem mais e suportam inconscientemente o que impõe a lógica do sistema, mas sem deixar de incluir nestas estratégias de mudança, os homens, na busca pela transformação de tudo e todos, homens e mulheres, conceitos e símbolos, em sujeitos sociais capazes de controlar suas condições de vida e intervir constantemente na orientação da dinâmica social que sempre foi e será cambiante de acordo com o lugar e o tempo.

Neste sentido se requer, como conclui Luiz Antônio Bogo Chies, uma criminologia-Pandora "uma criminologia que se proponha curiosa e compreensiva; uma criminologia que não produza criminosos e criminalizações, mas sim cognições desejantes de liberdade, que não apenas expliquem o passado e seus atores, mas se projete para o futuro" (CHIES, 2008. p.103).

A luta feminista e mais abrangentemente a luta antipatriarcal é travada e formada por meios e fins, entre os quais, seria necessário a utilização de ambas as possibilidades, uma para, mesmo que mantendo a lógica sem alterá-la substancialmente, permite alguns avanços momentâneos e diminuição de dores ocasionadas pelo encarceramento e, viabilize a manutenção da luta, a outra, em busca do fim, que apesar de ser talvez utópico, e incerto, possa não parecer tão inalcançável quanto à uma primeira leitura se afigure, a abolição as dores. Segundo Rose Marie: "As transformações necessárias para reverter o processo de distribuição do planeta são incomparavelmente maiores do que a revolução da mulher" (MURARO, 2002. p.195).

$\mathrm{E}$, assim, passar a uma menos volátil consciência de sua própria identidade e a propiciar o desenvolvimento da própria capacidade racional. Deixando de perceber como normal uma sociedade distribuída entre dominantes e dominados, opressão e submissão, ou criminosos e vítimas para visualizar uma sociedade mais plural e na qual o consenso seria não haver consenso, em uma constante discussão para a democracia de operacionalidade e viabilidade das relações.

1 O Grupo Interdisciplinar de Trabalho e Estudos Criminais-Penitenciários (GITEP) é um órgão inter e transdisciplinar, de natureza acadêmica e caráter permanente, que reúne docentes e discentes da Universidade Católica de Pelotas-RS, em torno de atividades de ensino, pesquisa e extensão que tenham por objetivo a promoção de reflexões e intervenções de conteúdo científico-crítico que viabilizem uma maior compreensão sobre as ciências criminais e penitenciárias e a realidade que as cercam, sob os enfoques das diversas disciplinas e campos científicos que àquelas se vinculam - grupo a que o autor pertenceu por 5 (cinco) anos e ainda mantém vinculação.

2 A pesquisa, intitulada 'A prisão dentro da prisão: uma visão do encarceramento feminino na $5^{\text {a }}$ Região Penitenciária do Rio Grande do Sul' foi coordenada pelo Prof. Dr. Luiz Antônio Bogo Chies e financiada pelo CNPq. Participaram da pesquisa os membros do Grupo Interdisciplinar de Trabalho e Estudos Penitenciários (GITEP) da Universidade Católica de Pelotas. São participantes da pesquisa: Dr a Ana Luísa Xavier Barros, Ms. Carmem Lúcia Alves da Silva Lopes; Ms. Marcelo Oliveira de Moura, Ms. Sinara Franke de Oliveira. Atuaram como bolsistas: Alexandre Melo Corrêa, Ms. Ana Carolina Montesano Gonzales Jardim, Cátia Gomes Shmidt, Gabriel Prestes Espiga, Jackson da Silva Leal, Josiane Costa Espanton e Ms. Sabrina Rosa Paz.

3 Pesquisa realizada entre fevereiro de 2006 e dezembro de 2008, contou com o autor como bolsista e colaborador na pesquisa que se desenvolveu in loco nos estabelecimentos prisionais mistos: Presídio Regional de Pelotas, Presídio Estadual de Rio Grande, Camaquã e Santa Vitória do Palmar.

$4 \quad$ O trabalho expõe resultados de uma pesquisa sobre o encarceramento feminino em presídios inicialmente masculinos. Desenvolvida com recursos do CNPq, através de dados da 5. ${ }^{\text {a }}$ Região Penitenciária do RS (prontuários, entrevistas e Grupos de Foco) abrange nuances destas opções político-penitenciárias: o incremento do encarceramento feminino associado a perfis de vulnerabilidade social e vinculado a delitos de entorpecentes e ao aprisionamento preventivo; a invisibilidade das encarceradas pela precarização dos espaços prisionais atribuídos, pelas ambíguas situações de exposição num ambiente masculino, por práticas administrativas e judiciais que lhes ofuscam como sujeitos de direitos, por suportarem sobrecargas de privações e dores prisionais, bem como por se encaixarem em dinâmicas que tendencialmente reproduzem os parâmetros de dominação masculina existentes na sociedade extramuros.

5 De acordo com dados do DEPEN Departamento Penitenciário Nacional. Disponível em: http://www.mj.gov.br/Depen/data/Pages/MJC4D50ED BPTBRIE.htm. 
6 Documento integral da CPI disponível em: http://www2.camara.gov.br/comissoes/temporarias53/c pi/cpis-encerradas/cpicarce/relatorio-apresentado-pelorelator-deputado.html.

7 Frei Betto. A marca do Batom: como o movimento feminista evoluiu no Brasil e no Mundo. In: http://alainet.org/active/1375\&lang=es

\section{Referências}

BADINTER, Elisabeth. Rumo equivocado: Feminismo e alguns destinos. Rio de Janeiro: Civilização Brasileira, 2005.

BAUMAN, Zygmunt. O mal-estar da pósmodernidade. Rio de Janeiro: Jorge Zahar Editor, 1998.

BAUMAN, Zygmunt. Modernidade e ambivalência. Rio de Janeiro: Jorge Zahar Editor, 1999.

BAUMAN, Zygmunt. Em busca da política. Rio de Janeiro: Jorge Zahar Editor, 2000.

BOURDIEU, Pierre. A dominação masculina. Rio de Janeiro: Bertrand Brasil, 2005.

BUGLIONE, Samantha. O Dividir da Execução Penal: Olhando Mulheres, Olhando Diferenças. In: CARVAlHO, Salo de (Org.) Crítica à Execução Penal: Doutrina, Jurisprudência e Projetos Legislativos. Rio de Janeiro: Lumen Juris, 2002. pp. 123-144.

CHIES, Luiz Antonio Bogo (et all). A prisão dentro da prisão: um olhar sobre o encarceramento feminino na $5^{\text {a }}$ região penitenciária o Rio Grande do Sul. Revista Brasileira de Ciências Criminais, v. 17, p. 251-280, 2009.

CHIES, Luiz Antonio Bogo. Gênero, Criminalização, Punição e 'Sistema de Justiça Criminal': Um olhar sobre as sobrecargas punitivas e as dominações do masculino. Revista de Estudos Criminais, v.8, n.28, p.81-105, jan./mar. 2008.

ESPINOZA, Olga. Feminismo e Criminologia. A mulher encarcerada em face do poder punitivo. São Paulo: IBCCrim, 2004.

ESPINOZA, Olga. A prisão feminina desde um olhar da criminologia feminista. Revista Transdisciplinar de ciências Penitenciárias. p. 35 - 59. 2002.
FLORES, Joaquín Herrera. De habitaciones propias y otros espacios negados: Una teoría crítica de las opresiones pratriarcales. Cuadernos Deusto de Derechos Humanos, no 33, p. 13 - 171, 2005.

GALEANO, Eduardo. De pernas pro ar: a escola do mundo ao avesso. Porto Alegre: L\&PM, 2007.

HARAWAY, Donna J. Manifesto ciborgue: ciência, tecnologia e feminismo-socialista no final do século XX. In: TADEU, Tomaz. Antropologia Ciborgue: as vertigens do pós-humano. Belo Horizonte: Autêntica, 2000 , p. $33-118$.

LEMGRUBER, Julita. A mulher e o sistema de justiça criminal. Revista Brasileira de Ciências Criminais. v. 9, n. 36, p.370-382, out-dez 2001.

LEMGRUBER, Julita. Da Privação à adaptação. In: LEMGRUBER, Julita. Cemitério dos Vivos - análise sociológica de uma prisão de mulheres. Rio de Janeiro: Forense, 1999, p. 91 - 115.

MURARO, Rose Marie. A mulher no terceiro milênio. Rio de Janeiro: Rosa dos Tempos, 2002.

MURARO, Rose Marie. Introdução Histórica. In: KRAMER, Henrich; SPRENGER, James. O Martelo das Feiticeiras. Rio de Janeiro, 2005, p. 5 - 17.

PATEMAN, Carole. Contrato Sexual. Rio de Janeiro: Paz e Terra, 1993.

PINTO, Céli Regina. Teorias da Democracia; diferenças e identidades na contemporaneidade. Porto Alegre: EDIPUCRS, 2004.

PRÁ, Jussara Reis. Gênero, cidadania e participação na esfera pública. In CARVALHO, Marie Jane Soares; ROCHA, Cristianne Maria Famer. (orgs.). Produzindo Gênero. Porto Alegre: Editora Sulina, 2004, p. 45-54.

SAFFIOTI, Heleieth I.B. O poder do macho. São Paulo: Moderna, 1987.

SANTOS, Boaventura de Sousa. Gramática do tempo: para uma nova cultura política. São Paulo: Cortez, 2006.

SCOTT, Joan W. O Enigma da igualdade. Revista de estudos feministas, v. 13, n. 1, p. $11-30,2005$.

SOARES, Bárbara Musumeci. ILGENFRITZ, Iara. 
Sobrecarga de Planos de Opressão e o Encarceramento Feminino no Sul do Rio Grande do Sul

Histórico e situação atual da prisão feminina no Rio de Janeiro. Prisioneiras: vida e violência atrás das grades. Rio de Janeiro: Garamond, 2002, p. 51-75.

STEARNS, Peter. História das Relações de Gênero. Tradução de Mirna Pinsky. São Paulo: Editora Contexto, 2007.

SWAIN, Tânia Navarro. Amazonas Brasileiras: impossível realidade? PADÊ: estudos em filosofia, raça, gênero e direitos humanos, v. 2, n. 1, p. 81-95, 2007.

TOURAINE, Alain. Um novo paradigma: para compreender o mundo de hoje. Petrópolis/RJ: Editora Vozes, 2006.

ZORDAN, Paola. Bruxas: Figuras de Poder. Revista de Estudos Feministas, v. 3, n. 2, p.331-341, maioagosto/2005. 